\title{
Development of Mosquito Protective Textiles Using Nanoemulsion of Eucalyptus Globulus and Syzygium Aromaticum Essential Oils Against Malaria Vector, Anopheles Stephensi (Liston)
}

\section{Zahra Sheikh}

Tehran University of Medical Sciences

Amir Amani

Tehran University of Medical Sciences

Hamid Reza Basseri ( $\sim$ basserih@tums.ac.ir)

Tehran University of Medical Sciences

Seyed Hassan MoosaKazemi

Tehran University of Medical Sciences

Mohammad Mehdi Sedaghat

Tehran University of Medical Sciences

Kamal Azam

Tehran University of Medical Sciences School of Medicine

Yaser Yousefpoor

Torbat Heydarieh University of Medical Sciences

Fatemehzahra Amirmohammadi

Ferdowsi University of Mashhad

Majid Azizi

Ferdowsi University of Mashhad

\section{Research Article}

Keywords: Mosquito repellent, Anopheles stephensi, Eucalyptus globulus, Syzygium aromaticum, Nanoemulsion

Posted Date: June 1st, 2021

DOl: https://doi.org/10.21203/rs.3.rs-446207/v1

License: (9) This work is licensed under a Creative Commons Attribution 4.0 International License. Read Full License 


\section{Abstract \\ Background}

The aim of current study was to determine the protection efficacy of Eucalyptus globulus and Syzygium aromaticum essential oils nanoemulsions-loaded textiles versus bulk essential oil- treated textiles against the malaria vector, Anopheles stephensi.

\section{Methods}

The components of E. globulus and S. aromaticum essential oils were determined using gas chromatography/mass spectrometry. Then, the nanoemulsions of both essential oils were prepared using a low energy emulsification method. Their stability and droplet sizes were determined, and the repellent efficacy against landings/bites of the starve mosquito females was examined using textile panels of polyester/cotton, impregnated with serial concentrations of the nano-emulsion.

\section{Results}

The main compositions of E. globulus essential oil were 1, 8-cineol (64.58\%) and alpha-pinene (10.63\%), whereas those of $S$. aromaticum essential oil were 2-methoxy-3-(2-propenyl) (77.04\%) and transcaryophyllene (11.99\%). Transparent oil in water nanoemulsion system consisting of essential oils, Tween-20, Tween-80 and propylene glycol was developed. The median droplet size was $11.2-23.1 \mathrm{~nm}$ depending on dilution ratio. Protection time of nanoemulsion-loaded textile ( $285 \pm 30 \mathrm{~min})$ was noticeably higher than that of bulk essential oils ( $<5 \mathrm{~min})$.

\section{Conclusions}

It was concluded that nanoemulsion of essential oils may be interesting options in control of mosquitorelated diseases.

\section{Introduction}

Mosquitoes are of the most important insects, which are nuisance vectors of different diseases such as malaria, dengue and filariasis [1]. According to World Health Organization report, malaria cases were 229 million worldwide in 2019 [2]. Among malaria vectors, Anopheles stephensi, vector of urban malaria, is an important vector with wide distribution and spreading in a large parts of Arabian Peninsula and certain countries of south east Asia include India, Afghanistan and Iran [3].

One of the principal strategies to protect human from the mosquito bites, is using of repellent gents. These agents are mostly available as lotions, gels, solution, creams and sprays. Mosquito repellents have 
been widely used and consist of natural or synthetic chemical compounds [4] [5]. Natural repellents using herbal essential oils are now being considered as alternative human safe and eco-friendly compounds for repelling mosquitoes and other insects [6].

Research and development in herbal repellents has been focused on increasing the longevity of their repellency properties and decreasing the evaporation rate of volatile components [6]. For instance, in a comparative study of repellency, effect of 38 essential oils, include Eucalyptus globulus and Syzygium aromaticum, in three concentrations (10\%,50\% and undiluted) was evaluated. 32 of them prevented mosquito bites in undiluted form [7]. It is interesting to note that some of essential oils (e.g. E.globulus and S.aromaticum) duration of repellency strongly depends on concentrations, experiment designs, and mosquito species [6].

The main ingredient of E. globulus essential oil is Eucalyptol. Eucalyptol is an aromatic component with a fresh camphor-like smell and a spicy, cooling taste. Generally, it is used as an insect repellent, insecticide, mosquito larvicide and ovipositional repellent with acetylcholinesterase inhibition activity [8].

Eugenol is the main extracted constituent (70-90\%) of clove and is responsible for clove aroma. Eugenol is a volatile phenolic constituent of clove essential oil obtained from S. aromatium buds and leaves, mainly harvested in Indonesia, India and Madagascar [9]. Eugenol is recognized as a relatively strong and moderately durable mosquito repellent [6].

In a study to achieve formulations of the plant-based mosquito repellents, using some plants including $E$. globulus and S. aromaticum (both of extract and essential oil) concentrations of $10 \%$ (V/V\%) were determined to be effective mosquito repellents [10]. While it was reported that the minimum effective concentration of soaked clove leaves (S. aromaticum) for repellency of Anopheles sp., was 1\% [11]. Furthermore, it was shown that the hexane extract of clove ( $S$. aromaticum) was more effective for repellency of malaria vector, An. stephensi, at 2.5, 5 and $10 \%$ concentrations [12].

Among the mosquito protection methods and mosquito repellent applications, a common method is use of textile-based mosquito protection in the form of nets, clothes, etc. [13]. According to Anitha et al., a mosquito repellent textile is a product which protects the human beings from the bite of mosquitoes [14]. Application of textiles treated with mosquito repellents to protect from the mosquito bites and mosquito borne disease such as malaria, is an innovate method (5).

The volatile components of essential oils are responsible for their repellent effects against mosquitoes. However, problems related to poor solubility and short-term stability of aromatic compounds of essential oils, hinder the development of effective essential oils formulations. Therefore, use of novel preparations such as nanoemulsions have been sugested [7] [15].

Nanoemulsions are colloidal dispersion systems composed of two immiscible liquids, mixed along with emulsifying agents (surfactants and co-surfactants) to form a single phase, with droplet sizes on the 
order of $100 \mathrm{~nm}$. Their small size leads to useful properties such as high surface area, robust stability, optically transparent appearance, and tunable rheology [16] [17].

The present study, focused on preparation of a nanoemulsion from E.globulus and S.aromaticum essential oils. Repellency efficiency of the treated fabrics with nanoemulsions was tested against $A n$. stephensi, using mosquito repellency cage test.

\section{Matherials And Methods}

\section{Essential oils}

E. globulus essential oil was purchased from Kesht-o-Sanate Golkaran Kashan Co, (Iran). The buds of clove (S. aromaticum) were grained by home grinder and hydro-distilled for $6 \mathrm{~h}$ in a Clevenger type apparatus in August 2019. The oil was dried over anhydrous sodium sulphate. The essential oils were kept in dark glass at $4-5^{\circ} \mathrm{C}$ in a refrigerator until analysis.

Water dilutions of $1 \%, 3 \%$ and $5 \%$ of $E$. gobulus as well as $0.5 \%, 1 \%$ and $3 \%$ of $S$. aromaticum essential oils were prepared. To find the mixing effects, three different combinations ratios of 1:1, 1:2 and 2:1 (v/v) according to the results of repellency tests of essential oil-impregnated textiles, were prepared.

\section{Chemicals}

Polyoxyethylene Sorbitan Monooleate (Tween-80) and Polyoxyethylene Sorbitan Monolaurate (Tween20) were purchased from SigmaAldrich, (Germany). Propylene Glycol was purchased form Kimyagaran Emrooz Co, (Iran).

\section{Analysis of essential oils}

The chemical composition of the essential oils was analyzed by gas chromatography-mass spectrometry (GC-MS). A gas chromatograph 7890B (Agilent Technologies, USA) equipped with a $30 \mathrm{~m}$ DB-5 capillary column $(0.25 \mathrm{~mm}$ inner diameter, $0.25 \mu \mathrm{m}$ film thickness) was used in combination with a mass spectrometer 5977A (Agilent Technologies, electron ionization detector). All injections were performed in split mode with auto sampler. Ten-microliter syringes were used to inject $1 \mu$ of samples. The injector temperature was set at $280^{\circ} \mathrm{C}$ and the flow rate was maintained at $1.0 \mathrm{ml} / \mathrm{min}$ using helium as the carrier gas. The initial oven temperature was set at $50^{\circ} \mathrm{C}$ for $5 \mathrm{~min}$ and ramped at $10^{\circ} \mathrm{C} / \mathrm{min}$ to $280^{\circ} \mathrm{C}$. The ion source and interface temperature were $230^{\circ} \mathrm{C}$ and $300^{\circ} \mathrm{C}$, respectively. The MSD was used in the electron impact (EI) full scan monitoring mode with a solvent delay time of $5 \mathrm{~min}$.

\section{Impregnating textile with the essential oil}

The textile fabric made of cotton: polyester (30:70) weighing 190 grams per square meter (Boroujerd Textile Co.) was used in the current study. The fabrics $(25 \mathrm{~cm} \times 25 \mathrm{~cm})$ were separately impregnated with different concentrations of essential oils and /or combination of both essential oils according to WHO protocol for impregnating the bed nets [18]. The repellency tests were separately performed for each 
concentration in four replications. Nanoemulsions were loaded on fabrics based on spray dying protocol [19]. The best ratio of essential oils combination with higher repellency efficiency was chosen to prepare the nanoemulsion. Deionized Water-treated fabrics were used as controls.

\section{Mosquitoes}

Adult females of An. stephensi, used in this study, were from the laboratory colonies reared and maintained in the Anopheles insectary of faculty of public health of Tehran University of Medical sciences $\left(28 \pm 2^{\circ} \mathrm{C}, 60 \pm 10 \%\right.$ relative humidity $(\mathrm{RH})$ and $12: 12(\mathrm{~L}: \mathrm{D})$ hours photoperiod). The mosquitoes were fed with $10 \%$ sugar solution and offered guinea pig blood twice in a week. In the present study, nonblood fed 2-5 day old females, starved for 4-6 hours prior to the bioassays, were used for repelling tests.

\section{Repellency bioassay}

In present study, repellency bioassays were conducted as previously described [20] [5]. A transparent Plexiglas box $(30 \times 30 \times 30 \mathrm{~cm}$ dimension) was used for accurate observation of the mosquito landing on the fabrics in the cage. Thirty mosquitoes were used for each repellency bioassay. The mosquitoes were simultaneously exposed to hand of a volunteer, which was covered with $25 \times 25 \mathrm{~cm}$ treated textile. The controls were essential oil free textiles. The exposed time was 5 minutes, each repellency test was performed in four replicates and protection time was considered as the time between the beginnings of test to the mosquito first landing.

\section{Nanoemulsion preparation}

Nanoemulsion of essential oils was formulated using a low energy emulsification method by magnetic stirrer at laboratory temperature (55 min, $1200 \mathrm{rpm}$ ). Initially, Tween 80 and Tween-20 were added to essential oil of E. globulus during stirring, then propylene glycol (co-emulsifier) was slowly added to the solution. Similar procedure was performed to prepare nanoemulsion of $S$. aromaticum (clove) essential oil using only Tween 80 as an emulsifier.

\section{Thermodynamic stability study}

The stability of prepared nanoemulsions was measured through visual observation. Freeze-thaw cycles were performed by keeping the emulsions at cycles of $-23^{\circ} \mathrm{C}$ and $25^{\circ} \mathrm{C}$ for $48 \mathrm{~h}$ at each temperature. Also the nanoemulsions were subjected to the thermodynamic stability tests by heating-cooling cycles $\left(4^{\circ} \mathrm{C}\right.$ and $40^{\circ} \mathrm{C}$ with storage of $48 \mathrm{~h}$ at each temperature). The cycles were repeated four times.

\section{Investigation of particle size and morphology}

The measurement of droplet size of nanoemulsion formulations was determined using Dynamic Light Scatteroscope I (K-One LTD., Korea). The morphological study of nanoemulsion was carried using Transmission Electron Microscopy (Philips EM208S, 100KV, Netherland).

\section{Statistical Analysis}


Data generated in repellency activity or protection time experiments using repellency bioassays were expressed as mean of repellency (min) \pm SD (Standard deviation). The data were then subjected to analysis of variance (ANOVA) followed by Post Hoc LSD test of multiple comparisons. All statistical analyses were performed by means of statistical software SPSS ver. 21.0 and the significance level was accepted when P-value $<0.05$.

\section{Results}

\section{Chemical analysis of essential oils}

According to GC-MS analysis, 12 compounds from E. globulus essential oil and 8 compounds from $S$. aromaticum essential oil were identified. The main components of the E. globulus essential oil were 1,8cineole (64.58\%), alpha pinene (10.63\%), benzene (8.31\%), (+) spathulenol (3.28\%) and (-)-globulol (2.60\%), which showed the retention times of $8.306,7.118,8.221,11.925$ and 11.963 min respectively (Table 1). The main components of $S$. aromaticum essential oil were phenol, 2-methoxy-3-(2-propenyl) (7 7.04\%), trans-caryophyllene (11.99\%), phenol, 2-methoxy-4-(2-propenyl) (6.83\%), alpha-caryophyllene $(1.40 \%)$ and beta-cadinene (1.21\%) with retention times of $10.721,11.113,11.559,11,290$ and 11.599 min, respectively (Table 2 ). 
Table 1

Components of Eucalyptus globulus essential oil from GC/MS analysis

\begin{tabular}{|llll|}
\hline No. & Compounds & $\mathbf{R t}^{*}(\mathbf{m i n})$ & Compositions (\%) \\
\hline 1 & Alpha pinene & 7.118 & 10.63 \\
\hline 2 & Benzene & 8.221 & 8.31 \\
\hline 3 & 1,8-Cineole & 8.306 & 64.58 \\
\hline 4 & Gamma.-Terpinene & 8.552 & 1.46 \\
\hline 5 & Bicyclo[3.1.1]heptan-3-ol & 9.274 & 1.91 \\
\hline 6 & 3-Cyclohexen-1-ol & 9.546 & 1.10 \\
\hline 7 & Alpha terpinolene & 9.637 & 1.30 \\
\hline 8 & (+)-Aromadendrene & 11.208 & 1.78 \\
\hline 9 & 1H-Cycloprop[e]azulene & 11.328 & 1.73 \\
\hline 10 & (+) Spathulenol & 11.925 & 3.28 \\
\hline 11 & (-)-Globulol & 11.963 & 2.60 \\
\hline 12 & 1-Propyl-3-(propen-1-yl)adamantane & 12.681 & 1.31 \\
\hline \multirow{2}{*}{ *Retention Time } & & 99.99 \\
\hline
\end{tabular}

Table 2

Components of Syzygium aromaticum essential oil from GC/MS analysis

\begin{tabular}{|llll|}
\hline No. & Compounds & $\mathrm{Rt}^{*}(\mathrm{~min})$ & Compositions (\%) \\
\hline 1 & Phenol, 2-methoxy-3-(2-propenyl) & 10.721 & 77.04 \\
\hline 2 & Alpha.-Copaene & 10.836 & 0.81 \\
\hline 3 & Trans-Caryophyllene & 11.113 & 11.99 \\
\hline 4 & Alpha.-Caryophyllene & 11.290 & 1.40 \\
\hline 5 & Delta.-Cadinene & 11.365 & 0.29 \\
\hline 6 & Phenol, 2-methoxy-4-(2-propenyl) & 11.559 & 6.83 \\
\hline 7 & Beta-Cadinene & 11.599 & 1.21 \\
\hline 8 & Caryophyllene oxide & 11.971 & 0.43 \\
\hline \multirow{2}{*}{ Total } & & 100 \\
\hline *Retention Time & & \\
\hline
\end{tabular}




\section{Physiochemical characterization of nanoemulsion}

The results of thermodynamic stability study on prepared formulations are shown in Table 3. After thermodynamic stress and based on visual appearance, 8 proportions were transparent and among them, formulations F5 (5\% E. globulus essential oil $+10 \%$ Tween- $80+8 \%$ Tween-20 + 10\% propylene glycol + $67 \%$ DW), F8 (5\% S. aromaticum essential oil $+22 \%$ Tween- $80+73 \%$ DW) and F15 (3\% E. globulus essential oil $+2 \%$ S. aromaticum essential oil $+7 \%$ Tween $-80+7 \%$ Tween- $20+16 \%$ propylene glycol $+65 \%$ DW) as $A, B$ and $C$ formulations were chosen for further studies due to their emulsifier content. Figure 1 shows the DLS results of the samples. The effect of dilution on particle size of the samples are indicated in Table 4. Comparison of the dilution effect on the median particle size $(\mathrm{nm})$ of $A, B$ and $C$ formulations is represented in Fig. 2. From the details, dilution has minimum effects on particle size of $\mathrm{C}$ formulation. Therefore, $C$ formulation was considered as the final preparation and investigated using TEM (see Fig. 3). The TEM image shows spherical shape for the particles with particle size of $8.5 \pm 3.0 \mathrm{~nm}$. 
Table 3

Effect of ingredients' concentration on visual appearance of the preparations after thermodynamic stability cycles

\begin{tabular}{|llllllll|}
\hline $\begin{array}{l}\text { Tube } \\
\text { Lable }\end{array}$ & $\begin{array}{l}\text { E. globulus } \\
\text { Essential } \\
\text { oil (\%) }\end{array}$ & $\begin{array}{l}\text { S. } \\
\text { aromaticum } \\
\text { Essential oil } \\
(\%)\end{array}$ & $\begin{array}{l}\text { Tween- } \\
\mathbf{8}(\%)\end{array}$ & $\begin{array}{l}\text { Tween- } \\
\mathbf{2 0} \\
(\%)\end{array}$ & $\begin{array}{l}\text { Propylene } \\
\text { glycol (\%) }\end{array}$ & $\begin{array}{l}\text { Water } \\
(\%)\end{array}$ & $\begin{array}{l}\text { visual } \\
\text { appearance }\end{array}$ \\
\hline F1 & 5 & 0 & 5 & 5 & 10 & 75 & Turbid \\
\hline F2 & 5 & 0 & 6 & 6 & 15 & 68 & Turbid \\
\hline F3 & 5 & 0 & 8 & 8 & 15 & 64 & Turbid \\
\hline F4 & 5 & 0 & 10 & 12 & 15 & 68 & Transparent \\
\hline F5 & 5 & 0 & 10 & 8 & 10 & 68 & Transparent \\
\hline F6 & 5 & 0 & 10 & 10 & 10 & 65 & Transparent \\
\hline F7 & 0 & 5 & 20 & 0 & 0 & 75 & Turbid \\
\hline F8 & 0 & 5 & 22 & 0 & 0 & 73 & Transparent \\
\hline F9 & 0 & 5 & 27 & 0 & 0 & 68 & Transparent \\
\hline F10 & 0 & 5 & 30 & 0 & 0 & 65 & Transparent \\
\hline F11 & 4 & 1 & 15 & 15 & 15 & 55 & Turbid \\
\hline F12 & 1 & 4 & 12 & 15 & 12 & 61 & Turbid \\
\hline F13 & 3 & 2 & 10 & 10 & 10 & 65 & Turbid \\
\hline F14 & 2 & 3 & 12 & 12 & 10 & 68 & Transparent \\
\hline F15 & 3 & 2 & 7 & 7 & 16 & 65 & Transparent \\
\hline
\end{tabular}


Table 4

Particle size of the selected nanoemulsions of $E$. globulus and $S$. aromaticum before and after

dilution with water

\begin{tabular}{|c|c|c|}
\hline Formulation & Dilution & Particle Size (nm) \\
\hline \multirow[t]{4}{*}{ F5 } & No dilution & 23.1 \\
\hline & $1: 5$ & 12.6 \\
\hline & $1: 10$ & 12.3 \\
\hline & $1: 20$ & 11.2 \\
\hline \multirow[t]{4}{*}{ F8 } & No dilution & 21.3 \\
\hline & $1: 5$ & 14.8 \\
\hline & $1: 10$ & 11.5 \\
\hline & $1: 20$ & 13.5 \\
\hline \multirow[t]{4}{*}{ F15 } & No dilution & 17.7 \\
\hline & $1: 5$ & 14.4 \\
\hline & $1: 10$ & 11.4 \\
\hline & $1: 20$ & 11.2 \\
\hline
\end{tabular}

\section{Repellency bioassays}

The protection time $(\mathrm{min}) \pm \mathrm{SD}$ of the impregnated textures with different concentrations and ratios of $E$. globulus and $S$. aromaticum essential oils as well as nanoemulsion-impegrated textiles are represented in Table 5. 
Table 5

Protection times of the textures impregnated with different bulk or nanoemulsion of essential oils against An. Stephensi mosquitoes

\begin{tabular}{|c|c|c|c|c|}
\hline Textile treatments & $\begin{array}{l}\text { Concentrations } \\
\text { or ratios of EOs } \\
\text { (v/v) }\end{array}$ & $\begin{array}{l}\text { Mean } \\
\text { protection } \\
\text { time (min) } \\
\pm \text { SD }\end{array}$ & $\begin{array}{l}\text { Standard } \\
\text { Error }\end{array}$ & P-Value \\
\hline \multirow[t]{3}{*}{ E. globulus EO* } & $1 \%$ & $\begin{array}{l}0.85 \pm \\
0.09^{b}\end{array}$ & 0.05 & 0.9640 \\
\hline & $3 \%$ & $3.00 \pm 0.23$ & 0.12 & 0.0004 \\
\hline & $5 \%$ & $3.82 \pm 0.20$ & 0.10 & 0.0002 \\
\hline \multirow[t]{3}{*}{ S. aromaticum EO } & $0.5 \%$ & $1.25 \pm 0.50$ & 0.25 & 0.0750 \\
\hline & $1 \%$ & $3.00 \pm 0.82$ & 0.41 & 0.0001 \\
\hline & $3 \%$ & $3.25 \pm 0.50$ & 0.25 & 0.00006 \\
\hline $\begin{array}{l}3 \% \text { v } / \mathrm{v} \text { E.globulus EO }+1 \% \mathrm{v} / \mathrm{v} \\
\text { S.aromaticum } \mathrm{EO}\end{array}$ & $1: 1$ & 2. $75 \pm 0.50$ & 0.25 & 0.00001 \\
\hline $\begin{array}{l}6 \% \text { v } / \mathrm{v} \text { E.globulus EO + } 1 \% \mathrm{v} / \mathrm{v} \\
\text { S.aromaticum } \mathrm{EO}\end{array}$ & $2: 1$ & $4.00 \pm 0.82$ & 0.41 & 0.000001 \\
\hline $\begin{array}{l}3 \% \text { v } / \mathrm{v} \text { E.globulus EO }+2 \% \mathrm{v} / \mathrm{v} \\
\text { S.aromaticum } \mathrm{EO}\end{array}$ & 1:2 & $\begin{array}{l}4.500 \pm \\
0.58\end{array}$ & 0.29 & 0 \\
\hline (Nanoemulsion) & $1: 2$ & $285 \pm 30^{\mathrm{a}}$ & 15 & 0 \\
\hline \multicolumn{5}{|l|}{$\begin{array}{l}3 \% \text { E. globulus EO + } 2 \% \text { S. aromaticum } \\
\text { EO + } 7 \% \text { Tween- } 80+7 \% \text { Tween- } 20+16 \% \\
\text { propylene glycol }+65 \% \text { DW }\end{array}$} \\
\hline Deionized Water (control) & - & $\begin{array}{l}0.08 \pm \\
0.07^{b}\end{array}$ & 0.04 & - \\
\hline \multicolumn{5}{|l|}{${ }^{\star}$ Essential Oil } \\
\hline \multicolumn{5}{|l|}{ a: significant deference with all groups } \\
\hline b: no significant deference according to $\mathrm{F}$ & Hoc (LSD) test ( & alue $=0.05)$ & & \\
\hline
\end{tabular}

According to Table 5, the protection times of impregnated textures, treated with E. globulus $1 \%$ and $S$. aromaticum $0.5 \%$ were less than 2 min and significantly lower than others ( $\mathrm{p}$-value $<0.05$ ). Furthermore, the protection time of textiles treated with E. globulus $1 \%$ and $S$. aromaticum $0.5 \%$ were not significantly different from water treated textiles as controls ( $p$-value $>0.05$ ). The protection times of impregnated textures, treated with E. globulus $3 \%$ and E. globulus $5 \%$ were not significantly different, as well as for the textiles treated with $S$. aromaticum $1 \%$ and $S$. aromaticum $3 \%$ ( $p$-value $>0.05$ ). Among the different 
combinations of essential oils (1:1, 2:1 and 1:2 ratios) based on the minimum effective concentrations of essential oils, the most effective combination was considered to formulate the nanoemulsions.

Accordingly, variety of formulations regarding to the fixed proportion of essential oils (5\%) were prepared and optimized, as already shown in Table 3. In total, nanoemulsion-impegrated textiles with E. globulus and $S$. aromaticum essential oils ( $3 \%: 2 \%$ ) showed the highest protection time ( $285 \pm 30 \mathrm{~min}$ ) compared with others (< $5 \mathrm{~min})$ (Table 5).

\section{Discussion}

The percentage of 1,8 cineole in chemical profile of E. globulus essential oil (64.58\%) was different from the 1.8 cinelole of the essential oil of E. globulus in previous reports collected from other countries such as Spain (63.8\%), India (68.8\%), Algeria (78.45\%), Italy (84.9\%), Montenegro (85.5\%) and China (94.30\%) [21] [22] [23].

Furthermore, the proportion of Eugenol and its derivatives in the essential oil of S.aromaticum (77.043) was different from those collected from other countries. Major components which were identified in the essential oil of S.aromaticum from Indonesia were m-Eugenol (69.44\%) and Eugenol acetate $(10.79 \%)$ [24]. While the main compositions of S.aromaticum from India were Eugenol (70\%), beta-caryophyllene $(19.5 \%)$ and Eugenol acetate (2.1\%). Those from Madagsacar were Eugenol (82.6\%), beta-caryophyllene (7.2\%) and Eugenol acetate (6\%) [25]. Previous studies indicated that the environmental factors including temperature, rainfall, humidity and solar radiation as well as the amount of soil macro- and micronutrients are able to influence the production of metabolites. Thus, plants under conditions of stress induced by climate factors may show changes in the production of different metabolites [26].

Previous researches have shown that attractiveness of human/ animal hosts to mosquitoes depends on the sensory cues (e.g. $\mathrm{CO}_{2}$, temperature and the quantity of components) which emit from the host's skin [27] [28] [29]. It is already known that at least 277 compounds [30], including ammonia, lactic acid and 1octen-3-ol (octenol), which are produced by human, are detected by the olfactory receptor neurons of mosquitoes [29]. The olfactory system of mosquitoes contains various protein receptors, connected to olfactory neurons, articulated in different parts of the mosquito body, particularly on the antennae and plays a key role in attraction towards human hosts [31]. However, some plant act as repellent or deterrent for mosquitoes as a protection strategy against the herbivores, pathogenic organisms, insects and pests [32] [26] [33]. The olfactory receptor neurons are responsible for the recognition of the repellent agents from these plants [29] [34]. Some volatile compounds which are detected by olfactory receptor neurons of mosquitoes, have the potential to be applied as repellents to decrease mosquito-human contact [7] [6] [35].

Essential oils, as a main class of herbal repellants [36] [31], are only effective when are freshly applied. They lose their repellency effects after a short time [7,37]. This issue has been resolved through preparing the formulations which are able to maintain the active ingredients on the skin for longer time 
periods. Formulations based on nano/microparticles not only increase the stability of the essential oils, but also facilitate their absorption into the skin/cloths, so, increase their repellency efficacy [36] [15].

Depending on the type of application, various methods have been used to determine the repellency properties of essential oils against mosquitoes including their dermal application [20] [38] [39] [10] [40]. The repellency activity of microemulsion of Eucalyptus (E. globulus) essential oil against field mosquitoes has been reported. The results indicated that microemulsions of 5,10 and $15 \%$ eucalyptus essential oil showed repellency activity for 82, 135 and $170 \mathrm{~min}$, respectively [41]. The repellency activity of nanoemulsified Mentha piperita and E. globulus essential oils against An. stephensi showed longer protection time compared with bulk essential oils of E. globulus and M. piperita [42]. There two studies agree with our findings in increasing the duration of effect of essential oil when formulated in a nanoemulsion. Other studies evaluate the repellency activity of impregnated textiles with essential oils. A study on textiles treated with microencapsulated citronella oil indicated higher and longer lasting protection compared to the textiles treated with an ethanol solution of the essential oil [43], similar to our results. This may be due to the lower rate evaporation of volatile components of essential oils in the nanemulsion formulation. In nanoemulsion particles, the inner phase (i.e. essential oil) is preserved in a layer of emulsifier molecules, therefore, evaporation of the essential oils molecules becomes less noticeable to form a slow and continuous release [44] [15]. In addition, the small particle size of the produced nanoemulsion $(\mathrm{d} 50<20 \mathrm{~nm}$ ) plays an important role in the increasing protection time, since nano-size particles probably have improved penetration into different materials including textile fibers [45] [15]. Moreover, it is well-known that the small size of the droplets allows them to be sprayed or deposited uniformly on target areas [44].

\section{Conclusion}

A high protection time from nano-formulation of E. globulus essential oil and S. aromaticum (clove) essential oil was reported. This indicates the effect of nano-formulation on fixing the volatile components as active ingredients of essential oils and reduction of evaporation rate from impregnated textiles. However, more investigations on nano-formulations of other essential oils with mosquito repellent properties, the synergistic effect of active components of mixed essential oils as well as their droplet size, thermodynamic stability and repellency effect after dilutions are required.

\section{Declarations}

\section{Acknowledgment}

The authors would like to thank School of Public Health, Tehran University of Medical Sciences, Tehran, Iran, for their assistance in carrying out this research.

\section{Ethics approval}


This research was approved by ethics committee of Tehran University of Medical Sciences (ir.tums.sph.rec.1397.244)

Consent for publication

Not applicable

\section{Availability of data}

The datasets used and analyzed during the current study are available from the corresponding author on reasonable request.

\section{Competing interests}

The authors declare that they have no competing interests.

\section{Funding}

This research was carried out by funding of Tehran University of Medical Sciences (Project No 40678)

Author information

Affiliations

Tehran University of Medical Sciences, School of Public Health, Tehran, Iran

Hamid Reza Basseri, Zahra Sheikh, Seyed Hassan Moosa Kazemi ,Mohammad Mehdi Sedaghat, Kamal Azam,

Tehran University of Medical Sciences, School of Advanced Technologies in Medicine, Tehran, Iran Amir Amani

Torbat Heydariyeh University of Medical Sciences, Research Center of Advanced Technologies in Medicine, Torbat Heydarieh, Iran

Yaser Yousefpoor

Ferdowsi University of Mashhad, Department of Horticultural Sciences, Faculty of Agriculture, Iran

Majid Azizi, Fatemehzahra Amirmohammadi

\section{Author's contributions}

The study came out from the corresponding author's graduate fieldwork. ZSh carried out the laboratory bioassays and field tests. AA supervised nano-synthetizing of essential oils, HRB as a main investigator has designed the project, supervised all procedure, SMK supervised mosquito bioassays, KA performed 
statistical analyze, YY advised nano-synthetized of essential olis, MA and FA extracted the essential oils. All authors read and approved the final manuscript.

\section{References}

1. WHO: Neglected Tropical deseases. 2016.

https://www.who.int/neglected_diseases/vector_ecology/en.

2. WHO: World Malaria Report. 2019. https://www.who.int/publications/i/item/9789241565721.

3. WHO: Vector alert: Anopheles stephensi invasion and spread. 2019.

https://www.who.int/news/item/26-08-2019-vector-alert-anopheles-stephensi-invasion-and-spread.

4. Rozendaal JA: Vector Control : methods for use by individuals and communities. World Health Organization 1997. https://www.who.int/whopes/resources/vector_rozendaal/en/

5. Anuar AA, Yusof, $N$. : Methods of imparting mosquito repellent agents and the assessing mosquito repellency on textile. Fash Text 2016. DOI: 10.1186/s40691-016-0064-y.

6. Maia M, Moore, S.: Plant-based insect repellents: a review of their efficacy, development and testing.Malaria journal 2011, 10 (suppl. 1) https://malariajournal.com/content/10/S1/S11.

7. Trongtokit Y, Rongsriyam, Y., Komalamisra, N., Apiwathnasorn, C.: Comparative Repellency of 38 Essential Oils against Mosquito Bites.Phytotherapy Research 2005, 19:303-309.

8. Tripathi AK, Mishra, S. : Plant monoterpenoides (prospective pesticides) in: Ecofriendly Pest Management for Food Security. Acacdemic press; 2016. https://doi.org/10.1016/C2014-0-04228-1.

9. Mohammadi Nejad S, Özgunes, H., Basaran, N. : Pharmacological and Toxicological Properties of Eugenol.Turk J Pharm Sci 2017, 14:201-206.

10. Ranasinghe MSN, Arambewela, L., Samarasinghe, S.: Development of Herbal Mosquito Repellent Formulations.International Journal of Collaborative Research on Internal Medicine \& Public Health 2016, 8:341-380.

11. Nindatu M, Noya, L. : Effectiveness of Clove Leaves (Syzygium aromaticum L.) Steeping Repellent to Anopheles Sp. .Journal Biologi Edukasi Edisi 21 2018, 10:17-20.

12. Singh SP, Mohan, L.: Mosquito Repellent activity of Syzygium aromaticum (clove) against Malaria Vector, Anopheles stephensi.Advances in Bioresearch 2014, 5:50-55.

13. Raja ASM, Kawlekar, S., Saxena, S., Arputharaj, A., Patil, P.G.: Mosquito protective textiles - A review.International Journal of Mosquito Research 2015, 2:49-53.

14. Anitha R, Ramachandran, T., Rajendran, R., Mahalakshmi, M.: Microencapsulation of lemon grass oil for mosquito repellent finishes in polyester textiles. Elixir Bio Phys 2011, 40:5196-5200. 
15. Echeverria J, Galhardo de Albuquerque, R.D.D. : Nanoemulsions of Essential Oils: New Tool for Control of Vector-Borne Diseases and In Vitro Effects on Some Parasitic Agents.Medicines 2019, 6:111.

16. Gupta A, Burak, H., Eral,T., Hatton, A., Doyle, P.S.: Nanoemulsions: formation, properties and applications.Soft Matter 2016, 12:2826-2841.

17. Gurpreet K, Sing, S.K.: Review of Nanoemulsion Formulation and Characterization Techniques.Indian J Pharm Sci 2018, 80:781-789.

18. WHO: Instructions for treatment and use of insecticide-treated mosquito nets, Use insecticide-treated mosquito nets to sleep in peace - and protect your health. 2002.

19. Mannouch S: Spray Gun Technique. IVW devilbiss, Industrial Training Center 1995:1-12. https://docplayer.net/53038351-Spray-gun-technique.

20. Phasomkusolsil S, Soonwera, M.: Insect repellent activity of medicinal plant oils against Aedes aegypti (Linn.), Anopheles minimus (Theobald) and Culex quinquefasciatus Say based on protection time and biting rate.Southeast Asian J Trop Med Public Health 2010, 41:831-840.

21. Barbosa LCA, Filomeno, C.A., Teixeira, R.R.: Chemical Variability and Biological Activities of Eucalyptus spp. Essential Oils.Molecules 2016, 21:1-33.

22. Atmani-Merabet G, Belkhiri, A., Dems, M. A., Lalaouna,A., Khalfaoui, Z., Mosbah, B. : Chemical composition, toxicity, and acaricidal activity of Eucalyptus globulus essential oil from Algeria.Curr Issues Pharm Med Sci 2018, 31:89-93.

23. Wang K, Tang, L., Zhang, N., Zhou, Y., Li, W., Li, H. et al. : Repellent and fumigant activities of Eucalyptus globulus and Artemisia carvifolia essential oils against Solenopsis invicta.Bulletin of Insectology 2014, 67:207-211.

24. Uddin MA, Shahinuzzaman, Md., Rana, Md. S., Yaakob, Z.: Study of chemical composition and medical properties of volatile oil from clove buds (Eugenia caryophyllus).IJPSR 2017, 8:895-899.

25. Srivastava AK, Srivastava, S. K., Syamsundar, K. V.: Bud and leaf essential oil composition of Syzygium aromaticum from India and Madagascar.Flavour Fragr J 2005, 20:51-53.

26. Sampaio BL, Edrada-Ebel, R. A., Batista Da Costa, F.: Effect of the environment on the secondary metabolic profile of Tithonia diversifolia: a model for environmental metabolomics of plants.Scientific RepoRts 2015, 6:1-11.

27. Steib BM, Geier M, Boeckh J: The effect of lactic acid on odourrelated host preference of yellow fever mosquitoes. Chem Senses 2001, 26:523-528.

28. Dekker T, Steib B, Cardé RT, Geier M: L-Lactic acid: a human-signifying host cue for the anthrophilic mosquito Anopheles gambiae.Med Vet Entomol 2002, 16:91-98.

29. Ghaninia M, Larsson M, Hansson BS, Ignell R: Natural odor ligands for olfactory receptor neurons of the female mosquito Aedes aegypti. use of gas chromatography-linked single sensillum recordings. The Journal of Experimental Biology 2008, 211:3020-3027. 
30. Bernier UR, Kline DL, Barnard DR, Schreck CE, Yost RA: Analysis of human skin emanations by gas chromatography/mass spectrometry. 2 . Identification of volatile compound that are candidate attractants for the yellow fever mosquito (Aedes aegypti).Anal Chem 2000, 72:747-756.

31. da Costa KS, Galúcio JM, da Costa CHS, Santana AR, Dos Santos Carvalho V, do Nascimento LD, Lima E Lima AH, Neves Cruz J, Alves CN, Lameira J: Exploring the Potentiality of Natural Products from Essential Oils as Inhibitors of Odorant-Binding Proteins: A Structure- and Ligand-Based Virtual Screening Approach To Find Novel Mosquito Repellents. 2019, 4:22475-22486.

32. Kessler S, Vlimant M, PM G: The sugar meal of the African malaria mosquito Anopheles gambiae and how deterrent compounds interfere with it: a behavioural and neurophysiological study.J VECTOR ECOL 2013, 216:1292-1306.

33. D B: Review on insecticidal and repellent activity of plant products for malaria mosquito control.Biomed Res Rev 2018, 2:1-7.

34. Nyasembe V, Tchouassi DP, Pirk CWW, Sole CL, Torto B: Host plant forensics and olfactory-based detection in Afro-tropical mosquito disease vectors.PLoS Neg/ Trop Dis 2018, 12:1-21.

35. Clark JT, Ray A: Olfactory Mechanisms for Discovery of Odorants to Reduce Insect-Host Contact.J Chem Ecol 2016, 42:919-930.

36. Nerio LS, Olivero-Verbel J, Stashenkob E: Repellent activity of essential oils: A review.Bioresource Technology 2010, 101:372-378.

37. Barnard DR: Repellency of essential oils to mosquitoes (Diptera: Culicidae).J Med Entomo/ 1999, 36:625-629.

38. Uniyal A, Tikar SN, Singh R, Shukla SV, Agrawal OP: Synergistic effect of effective oils against Aedes aegypti female mosquito, vector of dengue and chikungunya.Int J Mosq Res 2015, 2:29-35.

39. Tyagi V, Islam J, Agnihotri A, Goswami D, Rabha B, P.K T, al e: Repellent efficacy of some essential oils against Aedes albopictus.J Parasit Dis: Diagnosis and Therapy 2016, 1:1-5.

40. Ali A, Radwan MM, Wanas A, SKhan IA: Repellent Activity of Carrot Seed Essential Oil and Its Pure Compound, Carotol, Against Mosquitoes.J Am Mosq Control Assoc 2018, 34:272-280.

41. Navayan A, Moghimipour E, Khodayar MJ, Vazirianzadeh B, Siahpoosh A, Valizadeh M, Mansourzadeh Z: Evaluation of the Mosquito Repellent Activity of Nano-sized Microemulsion of Eucalyptus globulus Essential Oil Against Culicinae.Jundishapur J Nat Pharm Prod 2017, 12:1-6.

42. Mohammadi R, Khoobdel M, Negahban M, Khani S: Nanoemulsified Mentha piperita and Eucalyptus globulus oils exhibit enhanced repellent activities against Anopheles stephensi.Asian Pacific Journal of Tropical Medicine 2019, 12:520-527.

43. Miró Specos MM, García JJ, Tornesello J, Marino P, Della Vecchia M, Defain Tesoriero MV, L.G H: Microencapsulated citronella oil for mosquito repellent finishing of cotton textiles. Transactions of The Royal Society of Tropical Medicine and Hygiene 2010, 104:653-658.

44. Solans C, Izquierdo P, Nolla J, Azemar N, García-Celma MJ: Nano-emulsions.Curr Opin Colloid Interface Sci 2005, 10:102-110. 
45. Tadros T, Izquierdo P, Esquena J, Solans C: Formation and stability of Nanoemulsions.Advances in Colloid and Interface Science 2004, 108-109:303-318.

\section{Figures}
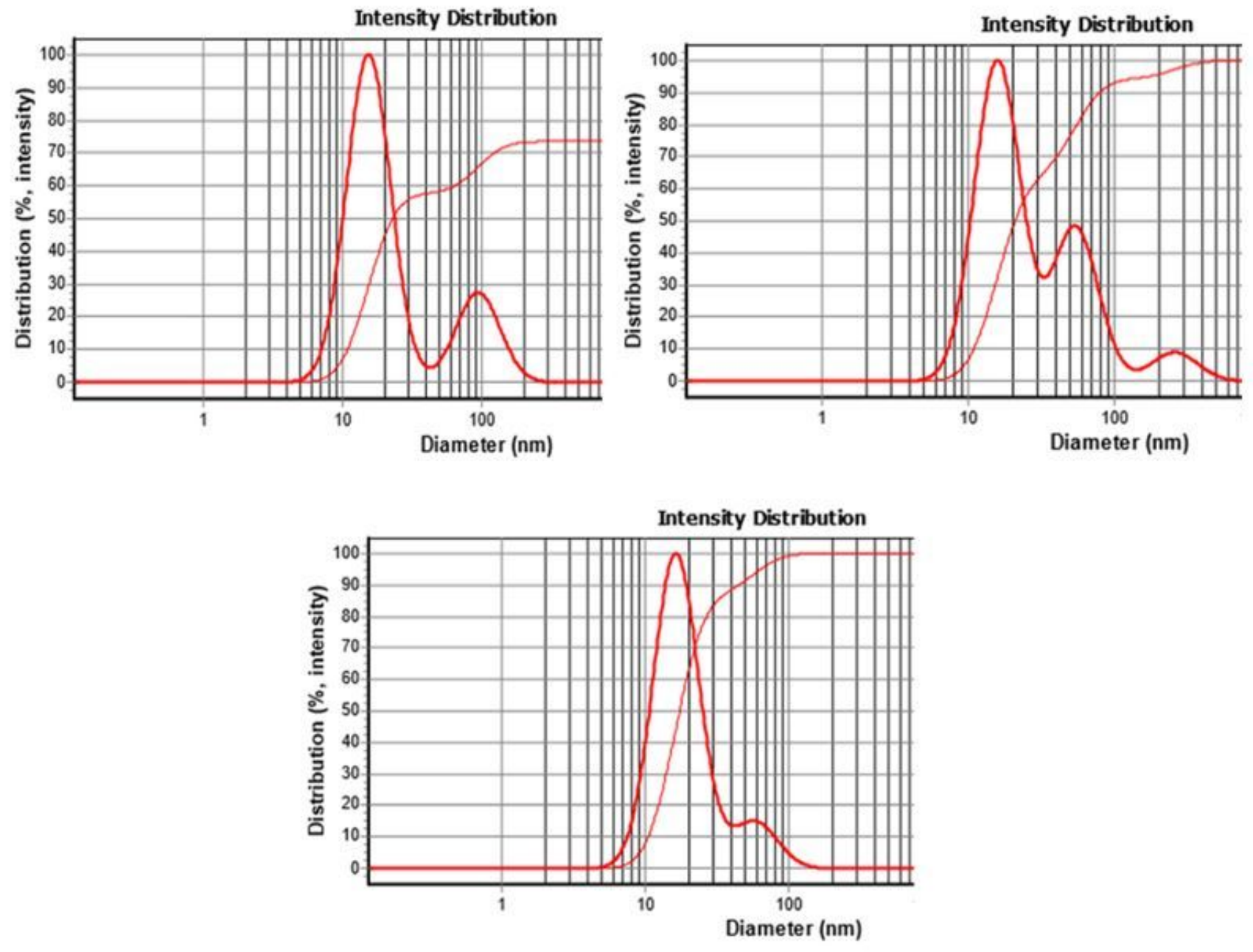

Figure 1

Particle size distributions for three formulations (A: up-left, B: up-right and C: down), using Dynamic Light Scattering 


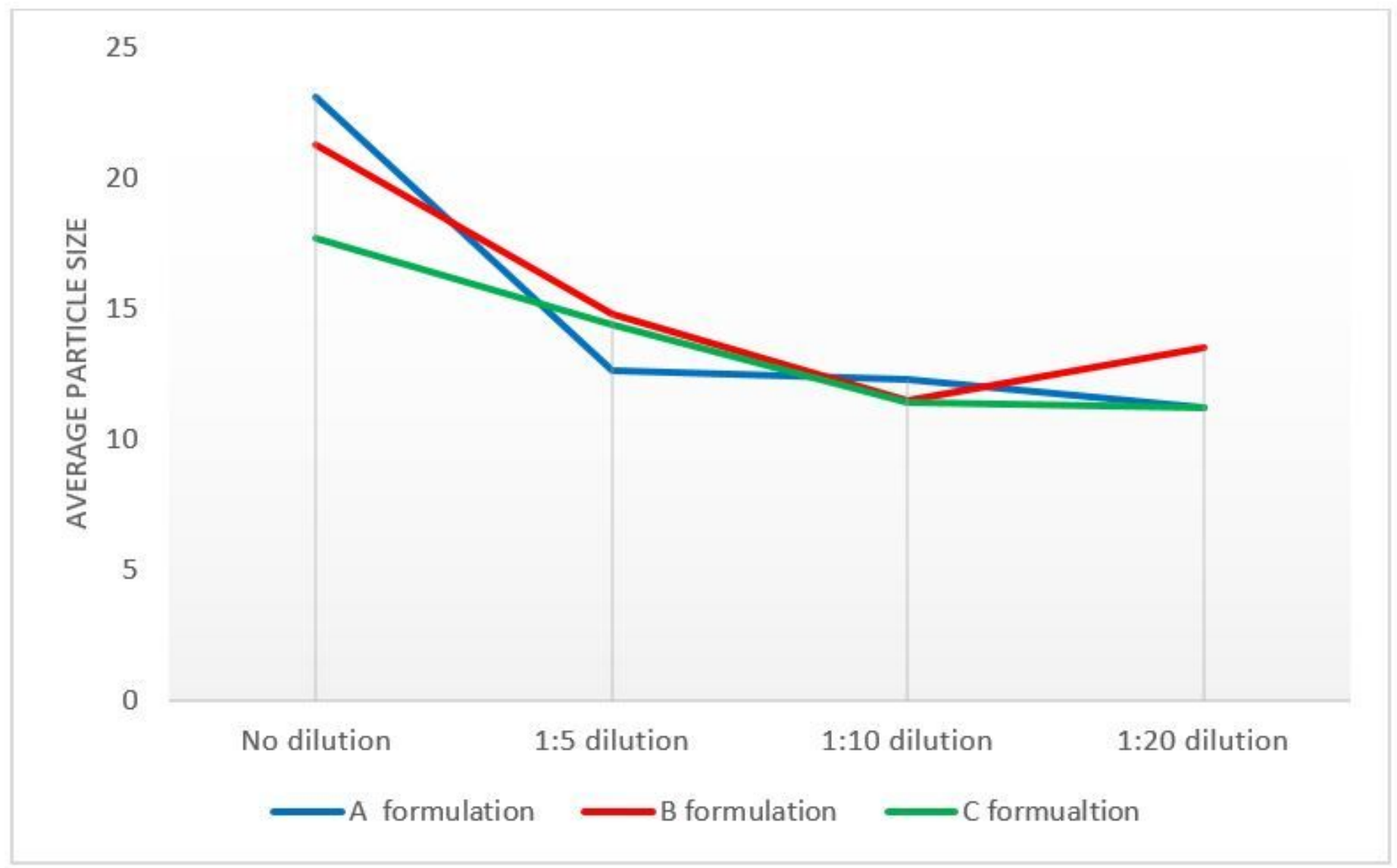

Figure 2

Comparison of the dilution effect on the average particle size $(\mathrm{nm})$ of three formulated nanoemulsions 


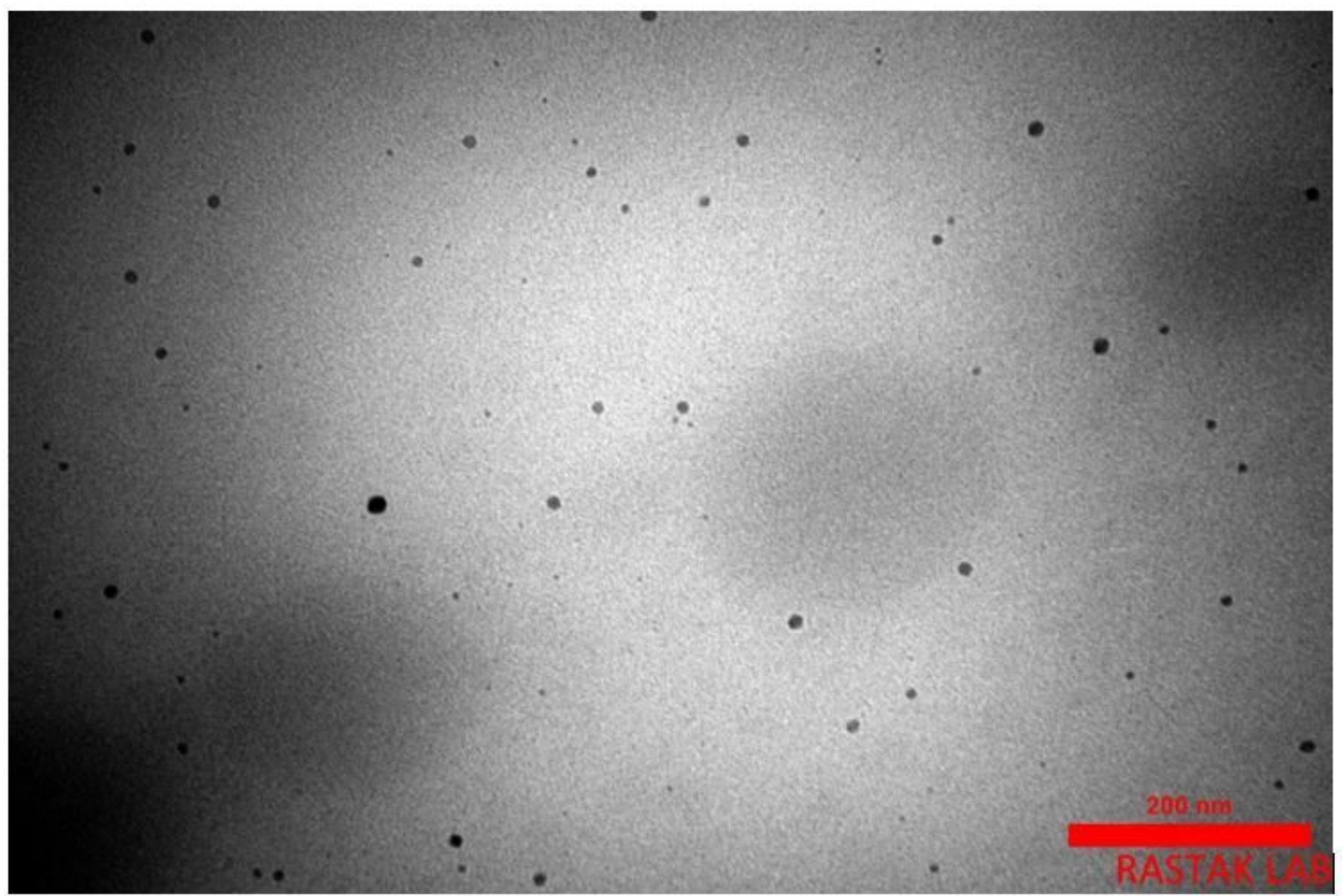

Figure 3

Morphology of nanoparticles of formulation C results from Transmission Electron Microscopy 